\title{
Employability, Curriculum of Higher Vocational Education and Human Resource Practice in Tourism and Hospitality
}

\author{
Ching-Yi Tsai \\ Graduate Institute of Education Administration, National Ping-Tung University of Education \\ E-mail:maggieyi0916@yahoo.com.tw
}

Accepted: Oct 03, 2013 Published: Oct 29, 2013

Doi:10.5296/jsr.v4i2.4481 URL: http://dx.doi.org/10.5296/jsr.v4i2.4481

\begin{abstract}
This study focuses on the question: which aspects of career employability of students of higher vocational education satisfy to tourism and hospitality sector in Taiwan, aimed at exploring current school curriculums provided as requested, correspond with the development of career employability among students of higher vocational education in Taiwan. The basis should accord with the expectation of the school's operational strategies, foster the strengths for the students, and improve employability for the students
\end{abstract}

Keywords: higher vocational education, curriculum design, employability, Tourism and hospitality

\section{Introduction}

Higher education have been expanded rapidly in many advanced countries, also especially higher Technical and vocational education in Taiwan, and transformed from the traditional pattern of the "elite", to a "mass", or even an "universal" pattern since 1980s. This expansion has provided the public with more opportunities to enter higher education in Taiwan, but whether such expansion has promoted the equity of higher education remains questionable with great concern.

We can look closely at the expansion of different sectors of the university system. Data indicate that private universities and colleges have grown much faster than public ones, in both enrollment numbers and number of schools. During the period from 1986 to 2006, undergraduate enrollment in public universities and colleges increased 2.67 times, while it increased 5.17 times in private sectors. This discrepancy in expansion is also shown in the composition of the entire undergraduate body. In this same period the proportion of undergraduates enrolled in private institutions, jumped from $62.5 \%$ to $73.7 \%$.

There is a broad consensus regarding the importance of generic skills in the modern workplace and also regarding the importance of ensuring that education and training systems develop these skills among young people in preparation for entry to the labor market. Shifts in employment towards services (which place a premium on interaction with clients), rapid 
technological change, especially computerization (which has been argued to have led to a shift towards employment in occupations involving complex communication and expert thinking), changes in work organization emphasizing teamwork, flexible production and multi-skilling and increasing competition and rapid change in consumer tastes have all been argued to increase demand for workers with broad-based thinking and interaction skills as well as technical competence and knowledge.

In this context, there have been a number of exercises that have sought to identify and group the key generic competencies needed in the modern workplace and that should be developed alongside occupational specific skills, particularly in preparing young people for entry to the labor market(DEEWR., 2012; Martin, \&, McCabe, \& Scott, 2007b). Most frameworks identify similar clusters of competencies: basic or foundation skills such as literacy and numeracy, higher-level cognitive skills such as problem solving and analytical reasoning, interpersonal skills such as communication, working in teams and ability to negotiate, ability to use technology particularly information communication techniques and learning skills such as knowing how to learn. These types of findings seem generalizable. A recent study of graduate employability in three Asian countries found that employers placed considerable emphasis on the possession of soft skills by university level graduates(UNESCOBangkok, 2012).

Ensuring a better match between the supply of and the demand for skills has emerged as a key issue for policy across the world. Concerns include the existence of persistent skill shortages, high rates of unemployment among particular population groups such as youth (which sometimes coexist with labor shortages), the oversupply of individuals with certain skills and types of qualification, and the failure of employers to make the most of the skills their employees possess.

Optimizing the use of skills has been identified as a central theme of the OECD Skills Strategy (OECD, 2011b) and by the World Bank in its framework for skills development (STEP)(WorldBank, 2010).

On the other side, an oversupply of graduates with higher education qualifications is seen as a problem in the Republic of Korea. Youth unemployment is high in economies such as Indonesia, the Republic of Korea, Taiwan, China and Hong Kong, China. (ILO, 2012). Making better use of the skills of the workforce has been identified as a central element of a proposed National Workforce Development Strategy in Australia (SkillsAustralia, 2010). Mismatch in the form of skills gaps and underemployment has become a topic of increasing interest to researchers and policy makers over recent years (CEDEFOP, 2010; Desjardins, 2011; OECD, 2011a). In fact, skills gaps have been argued to be a more serious problem than shortages(UKCES, 2009)

In looking at these issues, it is important to distinguish between qualifications mismatch and skills mismatch. Qualifications mismatch refers to a discrepancy between the highest qualification held by a worker and the qualification required by his/her job. Skills mismatch refers to a discrepancy between the skills - both specific and general - possessed by a worker and the skills required by his/her job (OECD, 2011a). Skills mismatch has been much less studied than qualification mismatch (largely because of data availability), and when it has been, it has been done so largely on the basis of subjective information. 
It is certainly far from clear that a broader general or liberal education is needed for the effective prosecution of many worthwhile human trades or services. It may be desirable that good auto-mechanics, chefs or hairdressers have substantial historical knowledge or enjoy reading poetry whenever they get the chance - and it may be hoped (for the enrichment of their lives) that they do have this wider commitment to liberal learning. But it is not at all obvious that a wide knowledge of history or poetry would much serve to make them better auto-mechanics, chefs or hairdressers. Thus, without denying that there may indeed be creative dimensions to auto-repair, cuisine and coiffure, any case for a broader liberal education rather than a more specifically focused training in the relevant skills of these trades and services might well be considered - for the purposes of adequate vocational training rather surplus to requirements.

\section{Literature Review}

Science, mathematics, history, art, cooking and carpentry feature on the curriculum, not bingo, bridge and billiards. Presumably there must be some reason for this apart from their utilitarian or vocational value(Peters, 1966).

(Peters, 1966, 1973) set out to discover this reason. During his enquiry, practical subjects like cooking dropped out of the picture, leaving 'theoretical enquiries' concerned with the pursuit of truth, like science, history and literary studies. Peters also collaborated with Paul Hirst, whose 'forms of knowledge' theory was published earlier, in 1965. This, too, sought to justify theoretical disciplines on intrinsic grounds. (Hirst \& and Peters, 1970)took these forms of knowledge as the basis for the curriculum.

The considerations of higher education in common and of university education in particular have long been subject to debate. However for some, the main part of universities is to provide professional and vocational education and training and their benefits are to be measured in terms of social or economic utility, their importance for others is to be seen more in terms of the liberal development and promotion of certain essentially worthwhile qualities of mind and intellect. In this context, certainly, much recent literature on university education has been concerned to restate what are usually taken to have been the liberal purposes of previous university education over the more instrumental or vocational programs of much contemporary university and higher education. While recognizing, along with other treatments of this issue, that it is to some extent concerned in an incorrect dichotomy between the liberal and the vocational. (Walmsley, Thomas, \& Jameson, 2012) It is necessary to seek a clearer rationale for the liberal dimensions and aspirations of university education.

More principally, still, much recent educational philosophy and theory has been concerned to toss doubt on the gap between the educational and the vocational observably presupposed to the classic liberal position. Thus, a good deal of recent work has been concerned to take to task the various distinctions (between theory and practice, intrinsic and extrinsic values, and so on) on which the liberal-vocational dichotomy seems to be constructed. Various alternative perspectives have also been proposed in response to such questions. One influential line of thought, developed - largely under the influence of John Dewey - by British educational philosophers (who have been especially exercised by the 
particularly sharp version of this distinction evident in local theorizing and policy making), proposes to 'close the gap' by recognizing the educational value of the practical and vocational and the instrumental or utilitarian value of the educational(Harvey, 2000) (Carr, 2006; Harvey, 2005). However, one trouble with this Deweyan remedy is that it seems more apparent than real - not least in so far as the 'solution' would appear to presuppose rather than dissolve the offending distinctions. From this viewpoint, indeed, it is arguable that some sort of distinction between educationally valuable and other sorts of learning is theoretically unavoidable(Sandberg, 2000). Further to this, it may have been one rather common mistake to neglect an important distinction between education and schooling. In terms of this distinction, it may rightly be seen as proper for schools (as tax-funded social institutions) to promote wider educational initiation as well as more narrowly or specifically focused training in vocational skills. To be sure, this does not at one stroke solve any or all problems of curriculum planning for elementary schooling, since policy makers would still seem stuck with the problem of how to balance the liberal and vocational claims on such schooling - of, as it were, how to weight the equally valid claims of (say) poetry and culinary skills. But this must remain no less of a problem for the new Deweyans - some of whom (such as Pring) would appear to incline (so far as one can see) to the liberal end of the spectrum, whereas others (such as Winch) lean more to the vocational end. That said, it should also be noted that yet others - no less uneasy with the classic liberal distinctions - have argued that training in narrowly conceived vocational skills has little or no clear warrant in the general educational contexts of common schooling(Dall'Alba, Gloria, \& Sandberg, \& Jörgen, 2006). Still, be that as it may, what might now be said of the liberal and/or vocational purposes of higher and university education?

Two common constructions are "employability as skills" and "employability beyond skills". The first construction refers to employability as attributes, attainable during higher education and directly applicable in working life whereas the second construction refers to employability as an integrated process, starting within higher education and continuing in working life.

According to (Maher, \&, Graves, \& Sarah, 2007)employability has particular relevance because of the diversity of industries and the volatility of employment within the sector. They point out that the trend in the service sector for employment above implies that different skill sets are required. Maher and Graves further argues the increasing importance of employability during recent years in three ways; the changing nature of the tourism and hospitality graduate labor market, the changing nature of the Higher education market as well as the changing expectations of Higher education stakeholders.

Discussing employability without relating the discussion to the concept of competence would be hard or even impossible. Above, the relation between Higher education and the work of graduates was described in terms of the discrepancy between the competence of the new graduates and the competence demanded from employers. The concept of competence and competence research are (as regards employability) wide and complex phenomenon. Several definitions and perspectives prevail, often without sorting out what is really meant. Several researchers have however described educational perspectives on competence(Dall'Alba, et al., 2006; Sandberg, 2000). 
According to (Sandberg, 2000), competence from a rationalistic perspective is looked upon as attribute-based. Those who perform most competently are supposed to own superior set of attributes (each determined in an absolute way, independent of context).

There is an array of tourism examples on how skills making graduates employable can be defined (Bibbings, 2001; Forbes, Peter, \& Kubler, \& Bianca, 2002; Martin, et al., 2007b). One example is (Arcodia, \&, Barker, \& Tanuja, 2003) who, departing from a study concerning job advertisements, have made a list of skills regarded important in event management jobs. They divide the list into three types of skills, general skills, practical skills and personality attributes, each group divided into smaller categories. All in all, 26 qualities desired in event management graduates are described. A similar example is (Martin, et al., 2007b)who departing from post graduate student survey, divides skills into personal qualities, core skills and process skills.

Tourism and hospitality programs may not have the tightly defined career progression routes that often follow from specialist qualifications in areas such as law or medicine (Becket, \&, Kemp, \& Patsy, 2006). Different case studies have shown that institutions and programs have addressed the issue of employability in a broad and rich rage of ways. Employability is located in, or could be developed through the curriculum in different ways. These approaches are often found in combination in courses. Different approaches can work effectively together. A broad range of perspectives on employability is possible to find in different case studies. As well different ways in which it has been incorporated within curricula is possible to find in different case studies. Examples can be shown on both institution wide and whole course developments, as well as implementation within individual modules and provision of learning relating to the real world within the curriculum (Becket, et al., 2006).

According to (Cranmer, 2006), development of skills has been addressed mainly in two ways in Higher education. Either the skills are embedded in subject matter teaching or offered as special modules aiming at skill development. Furthermore, Cranmer argues, these ways must be viewed as endpoints on a continuum. On one hand, a total embedding of skill development in courses can lead to students not at all aware of their own skill development. On the other hand, to "glue" skill developing modules or moments onto curriculum can result in students valuing them as less important, instead prioritizing subject knowledge.

Research from around 2000 showed that the embedded and integrated method works well regarding development of generic skills. When interviewing students prior to graduation, they could account relatively well for the situations in which they developed such skills. They were also aware of the range of skills addressed in curriculum and they could show evidence of the skills they argued they had (Cranmer, 2006). (De la Harpe et al., 2000) also points to the importance of integration concerning this.

(Hind, 2006) argues the importance of considering teaching and learning strategies to be used when conceiving an employability skills development program. Due to Hind, developing employability skills is a four stage process. The first step concerns making students aware and sensitive to the employability skills to be developed. The second step involves practice while the third is about getting feedback on practice. The final fourth step includes further practice in light of feedback. 
According to (Hind, 2006), course teams have three options when integrating a program of employability skills development into the curriculum. The first possibility is to integrate employability skills development into the curricula in a number of modules. Modules developing academic subject knowledge could have learning outcomes in relation to employability skills development. The second option is to design specific modules specifically focusing on development of employability skills. The third way is to use both ways. A reflection in the light of (Cranmer, 2006) model mentioned above, is that the two endpoints are represented in Hind's article, whereas the "middle" one, integration and explicit reflection is missing. However, Hind in his recommendations mentions encouraging students to be reflective learners as a great and crucial challenge in employability development.

So far this discussion has circled around employability development as skills. One conclusion is that an integrated model is to prefer but maybe not necessary for skill development. Maybe it has to relate to work in real contexts to be real powerful given its often contextual nature.

In the article by (Tribe, 2002) introduced above, the development of philosophical practitioners is intimately connected with development throughout the whole curriculum. His paper develops principles for ordering of curriculum for the ordering of tourism and hospitality higher education. The framework he is proposing, contains four key domains; vocational action, vocational reflection, liberal reflection as well as liberal action. As a whole these make use of practice, reflection over practice, perspective change as well alternative actions on a given problem. With this thinking we gather it is not possible to specify certain skills or applying modules or skill training accordingly. Rather it is about learning to act, learning to reflect, learning to use different perspectives and learning to choose the appropriate action according to the situation.

\section{Research question and research model}

However, empirical evidence which shows that a career-oriented learning environment as defined above will enhance the development of employability is lacking. The research presented here aims to provide an answer to the following questions:

(1) To what extent is the higher vocational education offer their students' employability?

(2) Which aspects of the higher vocational education are related to the use of employability by students? 

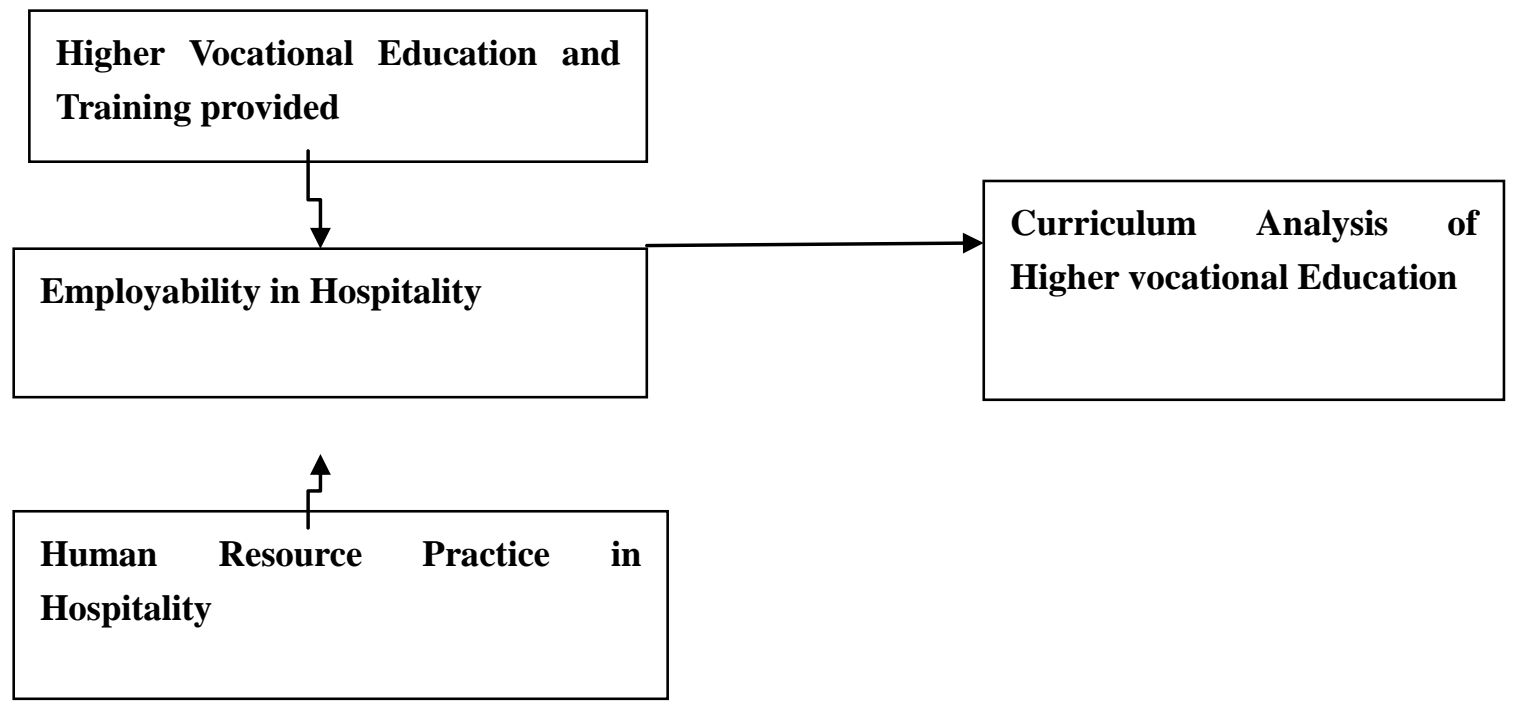

\section{Figure 1:The conceptual framework of this study}

\section{Method \\ Sample}

The study sample is drawn mainly from students of internship and staff of Human Resource separately in Hospitality. It drew out 300 questionnaires each division and received around 100 questionnaires back each.

\section{Construction of instruments}

The instrument used for collecting data from the students, a self-evaluation-based questionnaire of 26 items, was developed in 6 phases. First, an analysis was made of existing questionnaires in the area of employability. Since no existing instrument was found that was directly useful for this study, the report of the Commonwealth of Australia in 2002 became the foundation of the instrument used here to measure employability. The selected items were presented to each of the students in the form of a written, self-completion questionnaire.

The response categories of the items vary from $1=$ strongly disagree to $4=$ strongly agree On items about the learning environment the response category 'I don't know' was added. The questionnaire consisted of the following components.

The instrument used for measuring employability was based on a written, self-assessment questionnaire developed for the workplace. The Employability Skills Framework specifies eight skill groupings to describe and define employability skills(Huddleston \& Laczik, 2012). Monash University (2012) originally distinguished employability in hospitality; in the present case a model four factors of employability fitted best: learning skill, self-management skill, problem solving skill, Initiative and enterprise skill, teamwork skill, communication and interpersonal skill and technology skills .

\section{Research structure}

According to the purposes of this study, the author adopted a guideline provided by Churchill (1979). The overall process to measure the employability construct was divided into two parts. Part one contains the sample of generated items, and part two contains the data collection and 
purification of measures. Each of the two parts is depicted in Figure 2 and the developmental details are as follows.

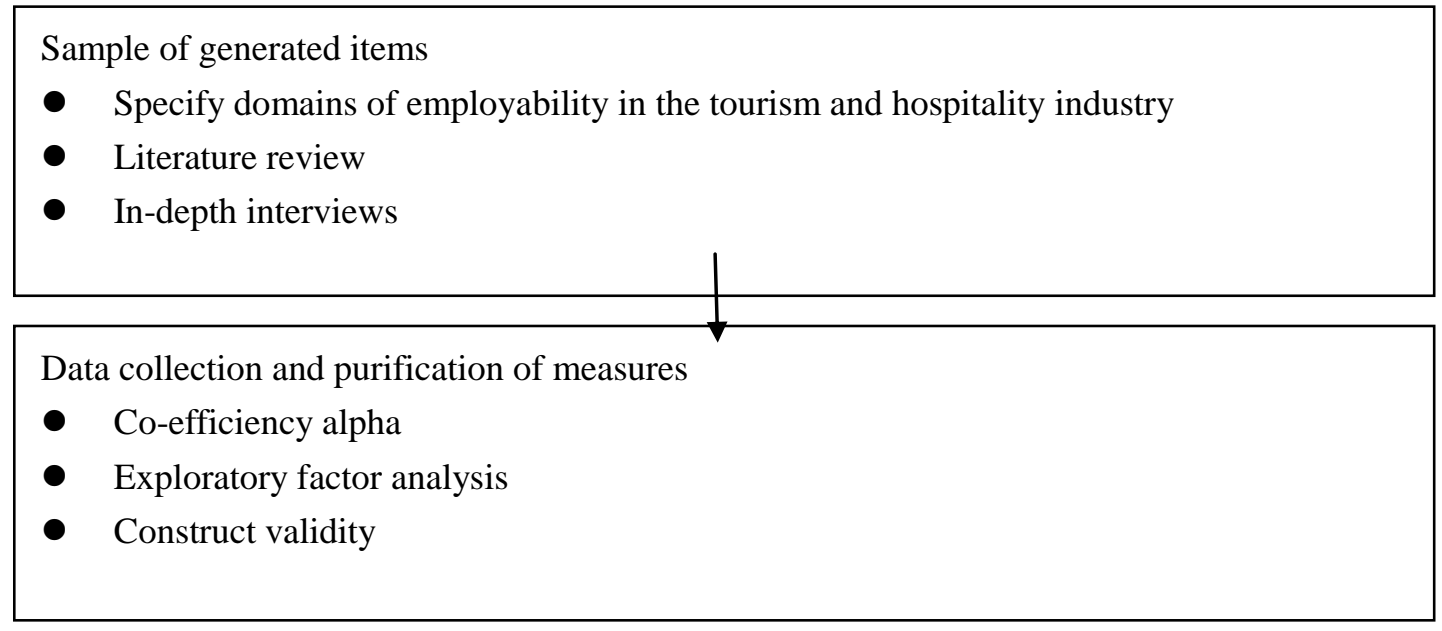

Figure 2: Flow chart of the research structure

\section{Sample of generated items}

According to Churchill's prescription, the research must be precise in delineating what is included or excluded in the definition(Churchill, 1979). To generate the items sample, two sources were employed: insights from the existing literature, and in-depth interviews.

\section{Purification of measures}

Initially, 32 items were rewritten to form an original questionnaire that was measured on a 5-point Likert scale. In order to precisely analyze them, we are supposed to target the diversities of all indicators. A high consistency among all is desirable. The consistency of a single item takes a coefficient alpha value 0.3 as a standard. Under this standard, Q27 and Q29 were eliminated from the study. Therefore, the study consisted of 30 items in total.

\section{Sample profile}

The study sample is drawn mainly from students of internship of higher education majoring in tourism and hospitality and staff of Human Resource separately in tourism and hospitality. Also conduct depth interview to the internship of higher education majoring in tourism and hospitality and managers of Human Resource separately in tourism and hospitality from the workplace in Taiwan.

The study collected data from two samples. They were conducted in April 2013. A total of 200 valid questionnaires formed the sample. A total of 200 responses were retained for analysis.

The profile of participants of staff of human resource (Sample 1) is shown in Table 3.71 . Among the 100 respondents, 56\% were female and 44\% were male. Most of them were 21-30 years old 16\%), followed by 31-40 years old (51\%), 41-50 years old (29\%) and above 50 years old (9\%). Educational levels were fairly high; nearly $89 \%$ had received a college degree or post-graduate education. Referring to their industry, $28 \%$ were tourism and sport, 
$70 \%$ were hospitality (hotel and restaurant) and $2 \%$ were air transportation. For the company size/numbers of employees, numbers of 1-100 (54\%), numbers of 101-200 (16\%), numbers of 201-300 (9\%) and numbers of above $300(21 \%)$. With respect to their job position, recruiting and hiring (33\%), training (30\%), salary and bonus (5\%), employee relationship (16\%), performance evaluating (5\%) and manager of department (11\%). Finally, the years of working, 1-3 years (42\%), 3-6 years (34\%), 7-10 years $(24 \%)$.

Regarding the profile of Sample 2,( Table 3) illustrates that the 100 of participants of internship were male (38\%) and female (62\%). Most of them were 21-30 years old (94\%), followed by 31-40 years old (6\%). Educational levels were fairly high; all of them were the internship of a junior college or college. With respect to their job position, $11 \%$ were clerical staff, $38 \%$ were service personnel, $14 \%$ were kitchen personnel, $11 \%$ were housekeeping, $16 \%$ were host, $9 \%$ were tour guide and $1 \%$ was cashier. Also, for the total years of working, within 1 year (30\%), 1-2 years (28\%), 2-3years (17\%), 3-4 years (15\%) and above 4 years $(7 \%)$.

\section{Sampling adequacy}

Prior to further analysis, the sampling adequacy test KMO measure

of the first sample $(n=100)$ was performed to determine the fitness of the data. The KMO of this study was 0.855 . And also the second sample $(n=100)$ was determine the fitness of the data. The KMO of this study was 0.859. According to Kaiser, a KMO of 0.70 is midrange(Kaiser, 1960). Therefore, the data for this study can be used for exploratory factor analysis (EFA).

\section{Exploratory factor analysis (EFA)}

This study used principal components as a method of extracting factors. In order to explain and label the factors, this study used the Varimax rotation to revolve the factor axis to make it clearer. Based on Hair and his colleagues' suggestions, this study kept items with a factor loading above 0.5 to increase its construct validity(Hair, 1998). There were 3 factors extracted (eigenvalue > 1) from the 30 items of employability for sample 1, with 2.603, 2.796 and 2.595 eigenvalue. Every employability variable had a clear factor loading on the three dimensions.

According to (Table 4), the first factor (Dimension 1) named Enterprise and self-management had $65.082 \%$ of the cumulated explained variance. Technology skill and interpersonal communication (Dimension 2) accounted for $69.896 \%$ of the cumulated explained variance. Problem solving (Dimension 3 ) accounted for $64.882 \%$ of the cumulated explained variance. With factor loadings of $0,854,0.763,0.705$ and 0.679 , it consists of 4 items for Enterprise and self-management (Dimension 1). Factor loadings of 0.833, 0.815, 0.811 and 0.718, it consists of 4 items for Technology skill and interpersonal communication (Dimension 2). Finally, Problem solving (Dimension 3), factor loadings of 0.838, 0.748, 0.644 and 0.621 and it consists of 4 items

There were 3 factors extracted (eigenvalue > 1) from the 30 items of employability for sample 2, with 3,564, 3.000 and 2.076 eigenvalue. Every employability variable had a clear factor loading on the three dimensions as shown in (Table 4).

According to (Table 4), the first factor (Dimension 1) named Self-management and learning had $71.280 \%$ of the cumulated explained variance. Enterprise and communication 
(Dimension 2) accounted for $59.995 \%$ of the cumulated explained variance. Planning and organization (Dimension 3) accounted for $69.2152 \%$ of the cumulated explained variance.

With factor loadings of $0,859,0.850,0.812,0.749$ and 0.642 , it consists of 5 items for Self-management and learning (Dimension 1). Factor loadings of 0.734, 0.732, 0.694, 0.693 and 0.649, it consists of 5 items for Enterprise and communication (Dimension 2). Finally, Planning and organization (Dimension 3), factor loadings of 0.877, 0.796 and 0.709 and it consists of 3 items

\section{Reliability analysis}

To establish the measurement reliability of the three-dimension factors, an internal consistency reliability coefficient was evaluated using a coefficient alpha measure (Cronbach's ،). The results showed that the alpha coefficients of all three factors ranging from 0.818 to 0.856 for sample 1 and 0.775 to 0.898 for sample 2 exceeded the recommended minimum level of 0.70 in accepting the reliability of factors(Hair, 1998). Accordingly, the four-dimension factors resulting from factor analysis in this research was proven to be reliable.

\section{Content validity}

Content validity is a tool used to measure the traits that the study needs. In order to test the variables precisely, this study ensures the integrity and importance of the selected items via literature and in-depth Interviews. Primary items came from literature reviews and they were discussed with professors and managers of human resource in the tourism and hospitality industry. Some rewritten items were reconfirmed through in-depth interviews. Before the data was collected, the researcher assessed the content and relevance of the variables.

\section{Conclusion and Implication}

Based on the guidelines of Churchill (1979), this study implemented a vigorous process to reach the study's goal. EFA was conducted to explore employees' employability structure. Three dimensions were finally identified: Problem-solving, empathy, enthusiasm, and friendliness. The composite reliability of the four dimensions were at least 0.7 , which demonstrated acceptable reliabilities. Validity was ensured through the examination of content validity, convergent validity, and discriminant validity.

The results of this study not only contribute to fill in a research gap, but also offer managerial implications for the tourism and hospitality industry's practitioners and educators. Interviews were undertaken with key senior managers to determine the views of individual enterprises on necessary employability skills, approaches to developing, tracking and assessing employability skills and how educational providers could play a more effective role in developing employability skills.

They also seek to broaden traditional approaches to education to include the wider community and, in the case of VET, require productive partnerships to be developed with industry.

The goals most specifically related to the development of employability skills include:

First, Schooling should develop fully the talents and capacities of all students. In particular, when students leave school they should:

- have the capacity for, and skills in, analysis and problem solving and the ability to communicate ideas and information, to plan and organize activities and to collaborate 
with others;

- have qualities of self-confidence, optimism, high self-esteem, and a commitment to personal excellence as a basis for their potential life roles as family, community and workforce members;

- have employment-related skills and an understanding of the work environment, career options and pathways to vocational education and training, further education, employment and lifelong learning;

- be confident, creative and productive users of new technologies, particularly information and communication technologies, and understand the impact of those technologies on society.

Second, In terms of curriculum, students should have participated in:

- programs of vocational learning during the compulsory years and have had access to vocational education and training programs as part of their senior secondary studies;

- programs and activities which foster and develop enterprise skills, including those skills that will allow them maximum flexibility and adaptability in the future.

Enterprises continue to focus on adaptation, cost reduction, increased productivity and new markets and/or new products and services. Enterprise choices with regard to recruitment and training are largely being driven by these business strategy directions. In this environment, there is an increasing requirement for employees to be able to support competitiveness, innovation, flexibility and customer focus.

Enterprises are seeking a more highly skilled workforce where the generic or general skills are broadly distributed across the organization. Considerable research both here and overseas has discussed the way in which people will work in the future. The action within some universities to specify generic skills as an overt outcome, allowing students' time to practice these and assess them, will assist graduates in understanding their employability potential and provide employers with an easier reference point.

Given the unique approaches taken by individual or groups of universities, DEST commissioned the ACER to develop a generic skills test (Graduate Skills Assessment Project) that could be used by universities to measure the development of skills in four areas:

- $\quad \square \quad$ Written Communication

- $\quad \square$ Critical Thinking

- $\quad \square \quad$ Problem Solving

- $\quad \square \square$ Interpersonal understandings.

It is not possible yet to determine the effectiveness and community and market acceptance of this test, given that it is still being introduced. However, it has the potential to assist employers in understanding a graduate's employability skills.

At the institutional level, it has become common practice for professional associations to contribute to the development of desired attributes of graduates.

\section{Curriculum aims and content}

This then brings to the fore the second issue: the stakeholders' views on the aims they deem appropriate for the tourism curriculum. For the three Caribbean islands under study, the consensus among the stakeholders is that the tourism curriculum should embrace both the vocational and liberal elements. The three main vocational aims of the tourism curriculum 
advocated by the stakeholders included the preparation of leaders for the local tourism industry with a particular focus on entrepreneurship, the development of industry specific and general transferable skills and an understanding and practical experience of service quality.

The main aim of a tourism degree is for the student to understand his/her role in national development. Tourism is not the end. Tourism is one of the means to an end. The end is to improve the quality of life of the people.

This perspective truly encourages liberal reflection in the tourism curriculum because her argument is that students must be able to critically analyze tourism in relation to national development. A tourism society where the development of tourism is planned, there is proper stewardship of the natural resources and the local culture is preserved. In other words, students must be prepared to work in tourism and for tourism.

The main aims identified by the stakeholders can be summarized as:

- To prepare students for key managerial roles in the tourism and hospitality industry

- To prepare students to develop and impart quality service

- To develop transferable skills

- To develop the student's ability to think flexibly and critically

- To gain a holistic understanding of tourism

- To develop a practical understanding of preserving the natural environment

- To enable the student to understand his/her role in national development

- To prepare students to contribute to the overall planning of tourism development

What is significant about this balance of knowledge in the tourism curriculum is that the student is offered more than a partial knowledge perspective that may limit and constrict understanding of the tourism phenomenon in the islands. This balance in knowledge enables students to better analyze the tourism phenomenon in the islands and places them in a better position to make informed decisions as potential leaders regarding the growth of tourism and hospitality. 


\begin{tabular}{|c|c|}
\hline $\begin{array}{ll}\text { Vocational Action } \\
\text { - } & \text { Tourism Marketing } \\
\text { - } & \text { HR Management } \\
\text { - } & \text { Business Development } \\
\text { - } & \text { Foreign Languages } \\
\text { - } & \text { Entrepreneurship } \\
\text { - } & \text { Quality Service } \\
\text { - } & \text { Information Technology }\end{array}$ & $\begin{array}{l}\text { Liberal Action } \\
\text { - Tourism and the Environment } \\
\text { - } \quad \text { Planning and Development } \\
\text { - } \quad \text { Sustainable Tourism }\end{array}$ \\
\hline $\begin{array}{l}\text { Reflective Vocational } \\
\text { - } \text { Problem Solving } \\
\text { - } \\
\text { Creative Thinking }\end{array}$ & $\begin{array}{l}\text { Reflective Liberal } \\
\text { - Tourism and Politics } \\
\text { Culture and Heritage }\end{array}$ \\
\hline
\end{tabular}

Figure 3: Curriculum Content

This implies a short-term, instrumental concern with knowledge - a pursuit of means of technical efficiency rather than the means to a stimulating and penetrating education. Following this, a gap has been unearthed within the context between the students' and teachers' understanding of the purpose of higher education for tourism and hospitality, and the nature of the current provision. At the same time as the stated focus of provision remains that of preparing graduates for the world of work in the tourism and other industries, teachers and students in tourism higher education take a broader perspective, seeking a deeper set of experiences. It is argued here that closing, or at least narrowing, this gap represents an outstanding challenge to tourism and hospitality higher education — a challenge that has meaning at all levels of scale and for most activities in tourism.

\section{Reference}

Arcodia, \&, C., Barker, \& Tanuja. (2003). The employability prospects of graduates in event management: Using data from job advertisements. R. W. Braithwaite \& R. L. Braithwaite. Riding the Wave of Tourism and Leisure Management.

Becket, \&, N., Kemp, \& Patsy. (2006). Introduction. Becket, Nina \& Kemp, Patsy red.Enhancing Graduate Employability in Business and Management, Hospitality, Leisure, Sport,

Tourism. Newbury: Threshold Press.

Bibbings, L. (2001). Tourism degrees and employability: Creative tensions in curricula.Link 
1.

Carr, D. (2006). Professional and personal values and virtues in education and teaching. Oxford Review of Education, 32(2), 171-183.

CEDEFOP. (2010). The skill matching challenge: Analyzing skill mismatch and policy implications. Luxembourg: Publications Office of the European Union.

Churchill, G. A. (1979). A paradigm for developing better measures of marketing constructs. Journal of Marketing Research, 16(1), 64-73.

Cranmer, S. (2006). Enhancing graduate employability: Best intentions and mixed outcomes. Studies in Higher Education, 31(2), 169-184.

Dall'Alba, Gloria, \& Sandberg, \& Jörgen. (2006). Unveiling Professional Development: A Critical review of Stage Models. Review of Educational Research, 76(3).

De la Harpe, Barbara, Radloff, \&, A., Wyber, \& John. (2000). Quality and Generic (Professional) Skills. Quality in Higher Education, 6(3), 231-243.

DEEWR. (2012). Employability skills framework stage 1 - Final report.

Desjardins, R., \& Rubenson, K. (2011). An analysis of skill mismatch using direct measures of skills (OECD Education Working Papers, No. 63).

Forbes, Peter, \& Kubler, \& Bianca. (2002). Employability: Employer perceptions of subject benchmark statements. London: The council for industry and higher education.

Hair, J. F., Anderson, R.E., Tatham, R.L., Black, W.C. (1998). Multivariate Data Analysis. New York:Prentice-Hall.

Harvey, L. (2000). New realities: The relationship between higher education and employment. Tertiary Education and management, 6(1), 3-17.

Harvey, L. (2005). Embedding and integrating employability. New directions for institutional research 128, 13-28.

Hind, D. (2006). Integrating employability and management skills into the tourism curriculum at Leeds Metropolitan University. The Higher Education Academy Hospitality. Hospitality, leisure, sport and hospitality network.

Hirst, P. H., \& and Peters, R. S. (1970). The Logic of Education (London, Routledge and Kegan Paul).

Huddleston, P., \& Laczik, A. (2012). Successes and challenges of employer engagement: the

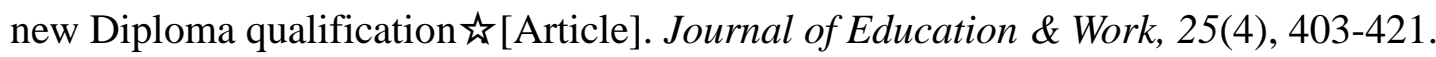

ILO, I. L. O. (2012). Global employment trends 2012. Geneva: International Labor Office.

Kaiser, H. F. (1960). The application of electronic computer to factor analysis. . Educational Psychology Measurements, 20(2), 454-465.

Maher, \&, A., Graves, \& Sarah. (2007). Making students more employable: Can higher education deliver? Paper presented at the EuroCHRIE Conference, Leeds, October.

Martin, \&, E., McCabe, \& Scott. (2007b). Part-time work and postgraduate students:Developing the skills for employment? Journal of hospitality, leisure, sport and tourism educational Leadership, 6(2).

OECD. (2011a). OECD employment outlook 2011.

OECD. (2011b). Towards an OECD skills strategy. Paris: OECD Publishing.

Peters, R. S. (1966). Ethics and Education (London, Allen and Unwin).

Peters, R. S. (1973). The Justification of Education, in: Hirst and White (1998) Vol 1. 


\section{Macrothink}

Sandberg, J. (2000). Understanding human competence at work: An interpretative approach. Academy of Management Journal, 43(1), 9-25.

SkillsAustralia. (2010). Australian workforce futures: A national workforce development strategy. Canberra: Skills Australia.

Tribe, J. (2002). The philosophic practitioner. Annals of tourism research, 29(2), 338-357.

UKCES. (2009). Ambition 2020: World class skills and jobs for the UK. London: UK Commission for Employment and Skills.

UNESCOBangkok. (2012). Graduate employability in Asia.

Walmsley, A., Thomas, R., \& Jameson, S. (2012). Internships in SMEs and career intentions. [Article]. Journal of Education \& Work, 25(1), 185-204.

WorldBank. (2010). Stepping up skills for more jobs and higher productivity. Washington: World Bank Group. 